\title{
Théophile Gautier, Viaggio in Italia. Venezia
}

\section{Valentina Ponzetto}

\section{(2) OpenEdition}

\section{Journals}

\section{Edizione digitale}

URL: http://journals.openedition.org/studifrancesi/5692

DOI: $10.4000 /$ studifrancesi.5692

ISSN: 2421-5856

\section{Editore}

Rosenberg \& Sellier

\section{Edizione cartacea}

Data di pubblicazione: 1 septembre 2011

Paginazione: 441

ISSN: 0039-2944

\section{Notizia bibliografica digitale}

Valentina Ponzetto, «Théophile Gautier, Viaggio in Italia. Venezia», Studi Francesi [Online], 164 (LV | II) |

2011, online dal 30 novembre 2015, consultato il 07 janvier 2021. URL: http://

journals.openedition.org/studifrancesi/5692 ; DOI: https://doi.org/ERREUR PDO dans /localdata/ www-bin/Core/Core/Db/Db.class.php L.34 : SQLSTATE[HY000] [2006] MySQL server has gone away

Questo documento è stato generato automaticamente il 7 janvier 2021.

\section{(c) (i) (9)}

Studi Francesi è distribuita con Licenza Creative Commons Attribuzione - Non commerciale - Non opere derivate 4.0 Internazionale. 


\title{
Théophile Gautier, Viaggio in Italia. Venezia
}

\author{
Valentina Ponzetto
}

\section{NOTIZIA}

THÉOPHILE GAUTIER, Viaggio in Italia. Venezia, a cura di Annalisa BOTTACIN, prefazione di Marie-Hélène GIRARD, traduzione di Annalisa BOTTACIN e Salvatore PISERCHIO, testo francese a fronte, Milano, La Vita felice, 2010, 670 pp.

1 La ventina di capitoli dedicati a Venezia del Viaggio in Italia di Gautier costituiscono la parte centrale nonché la più ricca e importante dell'opera, e compongono, come ricorda giustamente Marie-Hélène Girard nella prefazione, «uno dei principali viaggi a Venezia della letteratura francese, tanto per l'ampiezza quanto per l'interesse che Gautier porta alla città e alla sua cultura». Redatti in gran parte in loco, durante il soggiorno veneziano dello scrittore fra l'agosto 1850 e il 1851, poi completati sulla base di appunti presi dal vivo, essi furono pubblicati dapprima in feuilleton sulle colonne de «La Presse» di Émile de Girardin, che aveva in parte finanziato il viaggio, poi raccolti nel volume dal titolo Italia nel 1852.

2 La bella edizione testo a fronte curata da Annalisa Bottacin, che si segnala altresì per essere la prima a presentare una traduzione italiana dell'opera, li riunisce in un volume autonomo, il secondo dei tre in cui è suddiviso il Viaggio in Italia, incastonato fra $\mathrm{Da}$ Ginevra a Venezia (vol. I, Milano, La Vita felice, 2007, vedi «Studi Francesi» ${ }^{\circ} 159$ ) e $D a$ Venezia a Firenze (vol. III, di prossima uscita).

3 Nonostante nascano da un'esperienza vissuta e ricalchino fedelmente i vagabondaggi di Gautier, queste impressioni di viaggio non fanno praticamente mai allusione alle avventure personali dello scrittore, ma descrivono monumenti, usi e costumi con sguardo attento, distanziato, spesso venato di umorismo nell'evocazione di scenette curiose osservate sul posto. Ai grandi affreschi di chiese e palazzi, avidamente contemplati e minuziosamente descritti in una vera e propria «débauche 
visiva» (p. 655) - basti pensare ai due capitoli interi dedicati alla descrizione esterna e poi interna di San Marco, che prefigurano quasi l'analogo exploit di Michel Butor succedono degli acquerelli di vita quotidiana e l'esplorazione di una Venezia non convenzionale, periferica, povera, colta in tutto il realismo della realtà contemporanea. Analogamente, accanto all'ekphrasis preziosa e ricca di sensibilità artistica, Gautier è forse il primo ad offrire dei luoghi più celebri di Venezia un'immagine che prende in considerazione anche le pratiche turistiche che stanno via via prendendo piede, «dai mercanti di souvenirs che iniziano a invadere i portici delle Procuratie, ai ristoranti per turisti, passando per l'industria delle gondole o quella delle guide» (p. 12).

4 L'elegante traduzione sposa il ritmo e i preziosismi della prosa di Gautier, e restituisce al testo ulteriori tocchi di venezianità, ad esempio quando le ruelles ridivengono calli, o le places campi. Un ricco apparato di note, raggruppate alla fine di ogni capitolo, guida utilmente la lettura. 